$\Phi=$ 核

\title{
Both sides of the saffron's coin
}

\author{
Muhammad Torequl Islam $1,2 *$ \\ ${ }^{1}$ Department of Pharmacy, Southern University Bangladesh, Mehedibag (Chittagong)-4000, Bangladesh \\ ${ }_{2}^{2}$ Postgraduate Program in Pharmaceutical Science, Federal University of Piaui, Teresina (Piaui)-64.049-550, Brazil \\ *Corresponding authorE-mail: rbiotufpi.br@gmail.com
}

\begin{abstract}
Saffron (Crocus sativus L.), a popular traditionally-used compound is known for its promising beneficial health effects. However, it has been reported to have a number of toxic effects in human and other animals. This paper aims to summarize saffron's beneficial and toxic effects. The findings suggest that sufficient precautions are needed in using saffron and its constituents as they have both beneficial and toxicological impacts on human.
\end{abstract}

Keywords: Crocus sativus; saffron; traditionally-used compound; beneficial effects; toxicity.

\section{Introduction}

Saffron (Crocus sativus L.) has been used as a food additive for its color, taste and odor since ancient times (more than 3000 years ago) (Thorndike 1929) To date, both saffron and a number of its derivatives have been reported for some important biological activities (Aung et al. 2007; Mousavi et al. 2009; Samarghandian et al. 2010; Milajerdi et al. 2016). In parallel, saffron and its derivatives also reported to have some toxicological effects (HosseinZadeh et al. 2013; Taheri et al. 2014; Riahi-Zanjani et al. 2015). Therefore, this review aims to report both types of effects of saffron and its derivatives.

\section{Beneficial effects of saffron}

It is used as an amulet, cardiac medicament (cardiotonic), sedative (Thorndike 1929; Encyc. Brit. 1974), carminative, diaphoretic, emmenagogue (Grisolia 1974), abortifacient (Martindale 1941), anticoagulant (Ferrence and Bendersky 2004), styptic, soothing agent (Ferrence and Bendersky 2004; Giaccio 2004; Tolner 2005), hypnotic, diuretic, aphrodisiac, immunostimulator, antipoisonous, tonic (cardiac, livo and nervine), carminative, diaphoretic, emmenagogue, lactogogue, febrifuge, stimulant, relaxant, anti-stress, anti-anxiety, (Rios et al. 1996), anti-bacterial, anti-fungal, analgesic, anti-spasmodic, emmenagogue, diaphoretic.; and used in kidney and liver (enlargement) problems (Baumann 1960), appetite, catarrhal infections, for melancholia, (Encyc. Brit. 1974), atherosclerosis (Gainer and Chisolm 1974), dyspnea, problems of eye (inflammation, painful eye, blue discoloration, morbid matters, corneal disease and cataract, purulent eye infection) and head, menstruation, delivery and painful urination (Blois and Spek 2005; Tolner 2005), earache, tooth-ache, ulcers (skin, mouth, genitalia), erysipelas (Ferrence and Bendersky 2004; Giaccio 2004; Tolner 2005), refreshing and strengthening drugs (Abrishami 1997; Abrishami 2004), invigorate the body, strengthen senses, mood disorders, intoxication and preventing hangovers, major external bleedings, obstructions inside brain, severe headaches, insomnia, conjunctivitis, respiratory diseases, gout and joints, uterus pain, ulcers, pleurisy, refresh facial skin, coughs, diaphragmitis (Abrishami 1997), general debility, alcoholism, inflammation, diabetes, children's disorders (unknown etiology), insect bites, stings, edema, acne, skin diseases, wounds, depression, mental disorders, weak eyesight, asthma, sore throat and cold, vomiting, dyspepsia, prolapse of anus, dysmennhorea, impotency (both male and female), arthritis, apoplexy, and neurasthenia. saffaran and its derived components (e.g. - safranal, crocin) is evident to exert anticancer effects in a numner of cancer cell lines (Salomi et al. 1991; Garc-Olmo et al. 1999; Abdullaev 2002; Trujillo-Jiménez et al. 2004; Aung et al. 2007; Mousavi et al. 2009; Samarghandian et al. 2010; Milajerdi et al. 2016).

It can the regulate menstrual cycle as well. It is used in anal pain, stomach and spleen problems. It is useful in day blindness, lacrimation and keratitis. As an anti-inflammatory agent it can be used for swellings, otitis and wounds. It can reduce the resistance of coronary arteries and can improve blood circulation. It can be used in case of broken bones, dislocated joints, sprains, painful joints, purpura, eczema, rheumatoid arthritis, and measles.

\section{Toxicological effects of saffron and its de- rivatives}

The lethal dose $50 \%\left(\mathrm{LD}_{50}\right)$ values of saffron in mice are $4120 \pm$ $556 \mathrm{mg} / \mathrm{kg}$ and $1.6 \mathrm{~g} / \mathrm{kg}$ in oral (p.o.) intraperitoneal (i.p.), respectively (HosseinZadeh et al. 2013). For crocin (a component of saffron) the $\mathrm{LD}_{50}$ values found as $6 \mathrm{~g} / \mathrm{kg}$ (i.p.) (HosseinZadeh et al. 2013), while more than $3 \mathrm{~g} / \mathrm{kg}$ for oral (HosseinZadeh et al., 2010). For safranal (other components of saffron) the $\mathrm{LD}_{50}$ s was 5.53 to $21.42 \mathrm{ml} / \mathrm{kg}$ (p.o.) and 1.48 to $1.88 \mathrm{ml} / \mathrm{kg}$ (i.p.) in rats and mice (HosseinZadeh et al. 2013).

Repeated administration of saffron (i.p.: 350 to 3600 $\mathrm{mg} / \mathrm{kg}$; p.o.: 200 to $5000 \mathrm{mg} / \mathrm{kg}$ for 2-4 weeks) and its major constituents (stigma: (i.p.: 160 to $480 \mathrm{~g} / \mathrm{kg}$ for 2 weeks); crocin: (i.p.: 15 to $180 \mathrm{mg} / \mathrm{kg}$ up to 4 weeks); safranal: (p.o.: 100 to $500 \mathrm{ml} / \mathrm{kg}$ for 3 weeks)) are also evident to alter hematological (e.g. - hemoglobin $(\mathrm{Hb})$, hematocrit (HCT), red blood corpuscles (RBC), white blood corpuscles (WBC), and platelets) and biochemical (e.g. - alanine aminotransferase (ALT), aspartate amino- 
transferase (AST), urea, uric acid, blood urea nitrogen (BUN), creatinine, cholesterol, triglycerides (TGs), lon-density lipoprotein (LDL), alkaline phosphatase (ALP), malondialdehyde (MDA), fasting blood sugar, amylase, $\mathrm{Na}^{+}$, and gluthatione (GSH)) parameters, food intake, body weight, spermatogenesis index (e.g. repopula-tion index (RI), spermatogenesis index (SI) and tubular differentiation index (TDI)), alteration in the kidney and alveolar size in rodents (Karimi et al. 2004; Mohajeri et al. 2007; Modaghegh et al. 2008; Hosseinzadeh et al. 2010; Khayatnouri et al. 2011; Mohamadpour et al. 2013; Rezaee and HosseinZadeh 2013; Fadai et al. 2014; Taheri et al. 2014; Eaton et al. 2015; Muosa et al. 2015; Riahi-Zanjani et al. 2015).

The aqueous extract of saffron $(0.2-0.8 \%)$ was evident to reduce the tail length, biparietal diameter, placental diameter and weight of fetal during gestational period in $\mathrm{BALB} / c$ mice in a dose dependent manner (Zeynali et al. 2009). On the other hand, crocin (i.p.: 200 and $600 \mathrm{mg} / \mathrm{kg}$ ) and safranal (i.p.: 0.075 and $0.225 \mathrm{ml} / \mathrm{kg}$ ) disrupted skeleton formation as well as adversely affected in the weight, length, growth, mandible and calvaria of fetuses in mice (Moallem et al. 2013). Crocetin $(10-200 \mu \mathrm{M})$ was found to exert a teratogenic effect in frog (Xenopus) embryos, where a decreased in head-to-tail length and eye diameters was observed (Martin et al. 2002). Saffron is also evident to exert comutagenicity with BP (benzo[a]-pyrene) and 2AA (2-aminoantracene) in Salmonella typhimurium (Abdullaev et al. 2003).

Moreover, $400 \mathrm{mg}$ saffron tablets are evident to decrease in blood pressure (Modaghegh et al. 2008). Saffron is also found to increase the abortion rate in pregnant females (Ajam et al. 2014). Common adverse effects of saffron and its component products are: anxiety, appetite (decreased and increased), sedation, nausea, vomiting, headache, hypomania, dizziness, dry mouth, fatigue, restlessness, tachycardia, constipation, reflux, abdominal pain, drowsiness (daily and morning), nervousness, sexual dysfunction, tremor, sweating, heart pounding, insomnia, and urinary retention (Akhondzadeh et al. 2004; Akhondzadeh et al. 2005; Basti et al. 2007; Akhondzadeh et al. 2010; Mansoori et al. 2011; Shahmansouri et al. 2014).

Thus, adequate precautions should be taken in using saffron and its constituents as it has both benefits and toxicological impacts on human and other animals.

\section{Conflicts of interest}

None declared.

\section{References}

[1] Abdullaev F, Riveron-Negrete L, Caballero-Ortega H, Hernández JM, Perez-Lopez I, Pereda-Miranda R, et al. Use of in vitro assays to assess the potential antigenotoxic and cytotoxic effects of saffron (Crocus sativus L.). Toxicol in Vitro 2003; 17:731-736. https://doi.org/10.1016/S0887-2333(03)00098-5.

[2] Abdullaev FI. Cancer chemopreventive and tumoricidal properties of saffron (Crocus sativus L.). Exp Biol Med 2002; 227:20-25. https://doi.org/10.1177/153537020222700104.

[3] Abrishami MH. Persian Saffron, a Comprehensive Cultural and Agricultural History. Mashhad, Astan Ghods Razavi Publication 1997.

[4] Abrishami MH. Saffron, from yesterday till today, an encyclopaedia of its production, trade and use. Tehran, Amirkabir 2004.

[5] Ajam M, Reyhani T, Roshanravan V, Zare Z. Increased miscarriage rate in female farmers working in saffron fields: a possible effect of saffron toxicity. Asia Pac J Med Toxicol. 2014; 3:73-75.

[6] Akhondzadeh S, Fallah-Pour H, Afkham K, Jamshidi A-H, Khalighi-Cigaroudi F. Comparison of Crocus sativus L. and imipramine in the treatment of mild to moderate depression: a pilot doubleblind randomized trial [ISRCTN45683816]. BMC Complement Altern Med 2004; 4:12. https://doi.org/10.1186/1472-6882-4-12.

[7] Akhondzadeh S, Sabet MS, Harirchian MH, Togha M, Cheraghmakani H, Razeghi S, et al. A 22-week, multicenter, randomized, double-blind controlled trial of Crocus sativus in the treatment of mild-to-moderate Alzheimer's disease. Psychopharma- cology 2010; 207:637-643. https://doi.org/10.1007/s00213-0091706-1.

[8] Akhondzadeh S, Tahmacebi-Pour N, Noorbala AA, Amini H, Fallah-Pour H, Jamshidi AH, et al. Crocus sativus L. in the treatment of mild to moderate depression: a double-blind, randomized and placebo-controlled trial. Phytother Res 2005; 19:148-151. https://doi.org/10.1002/ptr.1647.

[9] Aung HH, Wang CZ, Ni M, Fishbein A, Mehendale SR, Xie JT, et al. Crocin from Crocus sativus possesses significant antiproliferation effects on human colorectal cancer cells. Exp Oncol 2007; 29:175-180.

[10] Basti AA, Moshiri E, Noorbala A-A, Jamshidi A-H, Abbasi SH, Akhondzadeh S. Comparison of petal of Crocus sativus L. and fluoxetine in the treatment of depressed outpatients: a pilot doubleblind randomized trial. Prog Neuropsychopharmacol Biol Psychiatry 2007; 31:439-442. https://doi.org/10.1016/j.pnpbp.2006.11.010.

[11] Baumann BB. The botanical aspects of ancient Egyptian embalming and burial. Econ Bot 1960; 14:84-104 https://doi.org/10.1007/BF02859368.

[12] Blois Ld and Spek RJvd. An Introduction to the Ancient World. Tehran, Ghoghnus 2005.

[13] Eaton DL, Gilbert SG. Principles of Toxicology. In: Kilassen CD, Watkins III Jb, editors. Casarett \& Doull,s Essentials of Toxicology. 3rd ed, New York: McGraw-Hill; 2015. p. 16-18.

[14] Encyclopaedia Britannica. Saffron. Macropaedia. Vol. 9, p. 891. Encyclopaedia Britannica, Chicago, IL 1974.

[15] Fadai F, Mousavi B, Ashtari Z, Ali BN, Farhang S, Hashempour S, et al. Saffron aqueous extract prevents metabolic syndrome in patients with schizophrenia on olanzapine treatment: a randomized triple blind placebo controlled study. Pharmacopsychiatry 2014; 47:156-161. https://doi.org/10.1055/s-0034-1382001.

[16] Ferrence SC and Bendersky G. Therapy with saffron and the goddess at Thera. Perspect Biol Med 2004; 47:199-226. https://doi.org/10.1353/pbm.2004.0026.

[17] Gainer JW, Chisolm GM. Oxygen diffusion and athersclerosis. Athersclerosis 194; 19:135-138.

[18] Garc-Olmo DC, Riese HH, Escribano J, Ontañón J, Fernandez JA, Atiénzar M, et al. Effects of long-term treatment of colon adenocarcinoma with crocin, a carotenoid from saffron (Crocus sativus L.): an experimental study in the rat. Nutr Cancer 1999; 35:120126. https://doi.org/10.1207/S15327914NC352_4.

[19] Giaccio M. Crocetin from Saffron: An Active Component of an Ancient Spice. Critical Rev Food Sci Nutr 2004; 44:155-172. https://doi.org/10.1080/10408690490441433.

[20] Grisolia S. Hypoxia, saffron, and cardiovascular disease. Lancet 1974; 2:41-42. https://doi.org/10.1016/S0140-6736(74)91367-1.

[21] HosseinZadeh H, Shakib SS, Sameni AK, Taghiabadi E. Acute and subacute toxicity of safranal, a constituent of saffron, in mice and rats. Iran J Pharm Res 2013; 12:93-99.

[22] Hosseinzadeh H, Shariaty VM, Sameni AK, Vahabzadeh M. Acute and sub-acute toxicity of crocin, a constituent of Crocus sativus $\mathrm{L}$ (saffron), in mice and rats. Pharmacologyonline 2010; 2: 943-951.

[23] Hosseinzadeh H, Shariaty VM, Sameni AK, Vahabzadeh M. Acute and sub-acute toxicity of crocin, a constituent of Crocus sativus $\mathrm{L}$ (saffron), in mice and rats. Pharmacologyonline 2010; 2: 943-951.

[24] Karimi G, Taiebi N, Hosseinzadeh H, Shirzad F. Evaluation of subacute toxicity of aqueous extract of Crocus sativus L. stigma and petal in rats. J Medicina Plants 2004; 4:29-35.

[25] Khayatnouri M, Safavi S, Safarmashaei S, Babazadeh D, Mikailpourardabili B. The effect of saffron orally administration on spermatogenesis index in rat. Adv Environ Biol 2011; 5:1514-1521.

[26] Mansoori P, Akhondzadeh S, Raisi F, Ghaeli P, Jamshidi A, Nasehi A, et al. A randomized, double-blind, placebo-controlled study of safety of the adjunctive saffron on sexual dysfunction induced by a selective serotonin reuptake inhibitor. J Med Plants 2011; 1:121130 .

[27] Martin G, Goh E, Neff A. Evaluation of the developmental toxicity of crocetin on Xenopus. Food Chem Toxicol 2002; 40:959-964. https://doi.org/10.1016/S0278-6915(02)00040-6.

[28] Martindale. The Extra Pharmacopoeia. 22nd ed. Pharmaceutical Press, London 1941.

[29] Milajerdi A, Djafarian K, Hosseini B. The toxicity of saffron (Crocus satious L.) and its constituents against normal and cancer cells. JNIM 2016; 3; 23-32.

[30] Moallem SA, Afshar M, Etemad L, Razavi BM, Hosseinzadeh H. Evaluation of teratogenic effects of crocin and safranal, active ingredients of saffron, in mice. Toxicol Ind Health 2013; 32:285-291. https://doi.org/10.1177/0748233713500818.

[31] Modaghegh M-H, Shahabian M, Esmaeili H-A, Rajbai O, Hosseinzadeh H. Safety evaluation of saffron (Crocus sativus) tablets in 
healthy volunteers. Phytomedicine 2008; 15:1032-1037. https://doi.org/10.1016/j.phymed.2008.06.003.

[32] Mohajeri D, Mousavi G, Mesgari M, Doustar Y, Khayat Nouri M. Subacute toxicity of Crocus sativus L. (saffron) stigma ethanolic extract in rats. Am J Pharmacol Toxicol 2007; 2:189-193. https://doi.org/10.3844/ajptsp.2007.189.193.

[33] Mohamadpour AH, Ayati Z, Parizadeh MR, Rajbai O, Hosseinzadeh H. Safety evaluation of crocin (a constituent of saffron) tablets in healthy volunteers. Iran J Basic Medical Sci 2013; 16:39-46.

[34] Mousavi SH, Tavakkol-Afshari J, Brook A, Jafari-Anarkooli I. Role of caspases and Bax protein in saffron-induced apoptosis in MCF-7 cells. Food Chemical Toxicol 2009; 47:1909-1913. https://doi.org/10.1016/j.fct.2009.05.017.

[35] Muosa F, AL-Rekabi K, Askar SJ, and Yousif EH. Evaluation of the toxic effect of ethanolic extract of saffron in male mice after subchronic exposure. Donnish J Pharm Pharmacol 2015; 1:1-7.

[36] Rezaee R, Hosseinzadeh H. Safranal: from an aromatic natural product to a rewarding pharmacological agent. Iran J Basic Med Sci 2013; $16: 12$

[37] Riahi-Zanjani B, Balali-Mood M, Mohammadi E, Badie-Bostan H, Memar B, Karimi G. Safranal as a safe compound to mice immune system. Avicenna J Phytomed 2015; 5:441-449.

[38] Rios JL, Recio MC, Giner RM, Manez S. An Update Review of Saffron and its Active Constituents. Phytpther Res 1996; 10:189$193 . \quad$ https://doi.org/10.1002/(SICI)1099 1573(199605)10:3<189::AID-PTR754>3.0.CO;2-C.

[39] Salomi M, Nair SC, Panikkar K. Inhibitory effects of Nigella sativa and saffron (Crocus sativus) on chemical carcinogenesis in mice. Nutr Cancer. 1991; 16:67-72. https://doi.org/10.1080/01635589109514142.

[40] Samarghandian S, Boskabady MH, Davoodi S. Use of in vitro assays to assess the potential antiproliferative and cytotoxic effects of saffron (Crocus sativus L.) in human lung cancer cell line. Pharmacogn Mag 2010; 6:309-314. https://doi.org/10.4103/09731296.71799

[41] Shahmansouri N, Farokhnia M, Abbasi S-H, Kassaian SE, Tafti AAN, Gougol A, et al. A randomized, double-blind, clinical trial comparing the efficacy and safety of Crocus sativus L. with fluoxetine for improving mild to moderate depression in post percutaneous coronary intervention patients. J Affec Disord 2014; 155:216222. https://doi.org/10.1016/j.jad.2013.11.003.

[42] Taheri F, Bathaie SZ, Ashrafi M, Ghasemi E. Assessment of crocin toxicity on the rat liver. Modares J Med Sci Pathobiol 2014; 17:6779.

[43] Thorndike L. A History of Magic and Experimental Science. Vol. 1, 605. Macmillan, New York 1929.

[44] Tolner R. Illustrierte Geschichte der Medizin. Tehran, Encyclopedia of medical history publications 2005 .

[45] Trujillo-Jiménez F, García-López P, Garcia-Carranca A, Abdullaev FI. Effect of saffron on the viability of normal and malignant human cells in vitro. Acta Hortic 2004:463-470. https://doi.org/10.17660/ActaHortic.2004.650.56.

[46] Zeynali F, Dashti MH, Anvari M, Hosseini SM, Miresmaeili SM Studying teratogenic an abortificant effects of different doses of saffron (Crocus sativus) decoction in whole gestational period and the 3 rd trimester of gestational period in mice. Int $\mathrm{J}$ Reprod Biomed $2009 ; 7$. 